\title{
The Model of the Constriction Resistance of a Sliding Electrical Contact
}

\author{
Igor Plokhov \\ Department of Drive and Automation \\ System \\ Pskov State University \\ Pskov, Russia \\ igor_plohov@list.ru \\ Oksana Kozyreva \\ Department of Drive and Automation \\ System \\ Pskov State University \\ Pskov, Russia \\ ks_33n@mail.ru
}

\author{
Igor Savraev \\ Department of Drive and Automation \\ System \\ Pskov State University \\ Pskov, Russia \\ igor_savraev@mail.ru \\ Nikita Kotkov \\ Department of Drive and Automation \\ System \\ Pskov State University \\ Pskov, Russia \\ 4ce@goodgame.ru
}

\author{
Alexander Markov \\ Department of Drive and Automation \\ System \\ Pskov State University \\ Pskov, Russia \\ markov-am55@mail.ru \\ Yulia Domracheva \\ Department of Drive and Automation \\ System \\ Pskov State University \\ Pskov, Russia \\ juli-politeh@yandex.ru
}

\begin{abstract}
This article is devoted to a theoretical study of the processes in a sliding electrical contact and the derivation of the formula for constriction resistance in the transient layer of electrical sliding contact taking into account the fractal heterogeneity of contact current-transmitting clusters, as well as the verification of the obtained theoretical formulas using a static experimental plant.
\end{abstract}

Keywords—brush, experimental plant, modeling, sliding contact.

\section{I.INTRODUCTION}

Each scale of heterogeneity of the contact zone of a sliding electrical contact (SEC) corresponds to the component of the general constriction resistance [1]. R.Holm proposed to consider two components corresponding to the constriction to the group of spots and corresponding to the constriction within the boundary of this group. Equation for bodies with the same resistivity $\rho$ containing one group of round uniformly distributed spots is derived:

$$
R_{r e t r}=R_{1}+R_{2}=\rho \cdot\left(\frac{1}{2 n a}+\frac{1}{2 a_{k}}\right),
$$

where $\mathrm{n}$ - the total number of contact spots; $\mathrm{a}$ - the radius of the spot; $\mathrm{a}_{\mathrm{k}}$ - the radius of the circle within which the contact spots are placed; R1, R2 - the resistance components corresponding to the constriction to the spots and to their groups.

J.A.Greenwod [18] specified clarified the second part of the equation:

$$
R_{\text {retr }}=R_{1}+R_{2}=\left(\frac{1}{2 n a}+\frac{16}{3 \pi^{2} a_{k}}\right)
$$

and showed that its value is almost the same for any location of contact spots in the general group.

The Greenwood equation was extended by terms that took into account the asymmetry of the spot groups distribution (clusters) on each other as well as the

asymmetry of the groups distribution on the nominal area [2], [8-9], [21].

Theory of the electrofriction interaction is currently at a critical stage which is characterized by a large number of accumulated empirical data, hypotheses and various types of models that can not sufficiently claim the adequacy of the presentation of the studied phenomena. To overcome these contradictions, it is necessary to attract new physical views and ideas to this applied area of knowledge.

The theory of self-organizing systems (synergetics and the fractal theory) is rapidly developing nowadays. These systems are self-similar evolutionary structures which cannot be described using Euclidean geometry.

The synergetics studies the processes of selforganization, of stability and of decay of structures of different nature formed in open systems, the ordered state of which is related to the consistent behavior of the subsystems. It leads to the formation of organized structures as a result of the exchange of energy and matter with the environment, when a certain balance between a production and a reduction of entropy is established [3-4], [11]. The evolution of the system considers as a transition through a number of thermodynamic quasi-equilibrium states. Fractal theory [5-6] was the basis for quantitative description of self-organizing structures using the fractal dimension parameter.

The processes of electrofrictional interaction will be considered from the standpoint of the synergetics and of the fractal theory, because the sliding electrical contact is an open system and evolutionary processes of the origin and decay of conducting clusters, which can be interpreted in the tangential direction as fractal and in the radial direction as percolation clusters, there are in the intermediate layer [6], [12], [17], [19-20].

From told above we can conclude that on the problem of explaining the mechanism of current transfer through sliding contact a one frame of mind has not yet developed. There are different interpretations of the processes of current transfer in the intermediate layer. It leads to the 
fact that the most reliable and frequently used means of studying of the properties and of the characteristics of sliding contact today is an experiment. This situation is also due to the absence of modeling software products for calculating the basic integral characteristics of the sliding contact according to the data containing the parameters of contacting bodies, their surfaces, as well as external energy influences.

Therefore, work aimed at creating computational models that allow one to obtain static and dynamic characteristics of brush-contact device by calculation at the design stage are very relevant.

\section{MATERIALS AND METHODS}

The direct conductivity in the sliding contact occurs when the microasperities in the intermediate layer of the contacting microreliefs come into direct contact. In addition, we will assume that as a result of fritting, conductivity similar to the direct conductivity also occurs.

The main component of the transient resistance of the sliding electrical contact is the constriction resistance, which is caused by the distortion of the current lines in the region of each individual contact spot of rough surfaces. Many scientific works are devoted to studies of contact conductivity and constriction resistance, for example [7], [10], [23].

To determine the transient resistance in the computational models of the electrofriction interaction it is necessary to define a mathematical expression for the intermediate resistance of an individual contact cluster. Therefore, we will derive mathematical expressions that give a topological and fractal representation of the constriction resistance and compare the obtained results with the known ones.

In the simplified version of the calculation we will set a single round contact spot of radius ro. Such unification in a single area is acceptable with a sufficiently compact placement of conducting clusters. We will divide the surrounding half-space into two zone $\mathrm{A}$ and $\mathrm{B}$ for determination the constriction resistance. The zone $\mathrm{A}$ is bounded by the hemisphere of the spot of the contact with radius $r$, and the zone $B$ is bounded by the hemisphere with radius $r_{m} \gg r_{0}$. Let's call these areas in accordance with their placement of a relatively small "contact" hemisphere: A - "internal", B - "external".

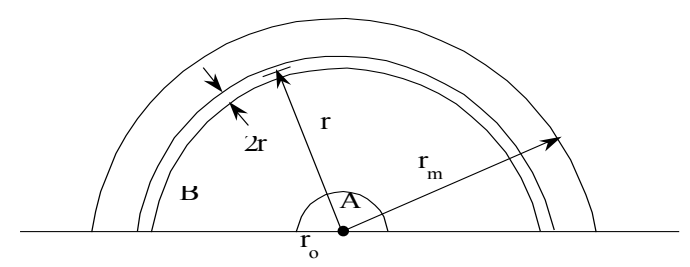

Fig.1. Approximate definition of the constriction resistance of the round spot of contact.

Selecting the volume located between two spheres with radius $\mathrm{r}+\mathrm{dr} / 2$ and $\mathrm{r}-\mathrm{dr} / 2$ in zone $\mathrm{B}$ we determine the resistance $\mathrm{dRB}$ of this layer in the direction of the current lines:

$$
d R_{B}=\rho \frac{d r}{2 \pi r^{2}}
$$

The current lines in zone B are directed radially and the specified spherical volume is limited by equipotential surfaces. In this case we assume that the current lines connect the superconducting spheres with radius $r_{o}$ and $r_{m}>r_{0}$. Then the resistance $R_{B}$ of the zone $B$ is determined by integrating of the previous formula:

$$
R_{b}=\frac{\rho}{2 \pi} \int_{r 0}^{r_{v}} \frac{d r}{r^{2}}=\frac{\rho}{2 \pi}\left(\frac{1}{r_{0}}-\frac{1}{r_{r w}}\right)
$$

Taking into account that $r_{m}>r_{o}$, we find the "external" component of the constriction resistance by the formula:

$$
R_{B}=\frac{\rho}{2 \pi r_{0}}
$$

We define the "internal" component approximately from the consideration of replacing a hemisphere with a cylinder with the equivalent height and the same area of the base and with non-conducting side walls. We find the height of the cylinder by the condition of equality of the volumes of the hemisphere and the cylinder:

$$
h=\frac{2}{3} r_{0} ; R_{A}=\frac{\rho}{6 \pi r_{0}}
$$

Then the total constriction resistance is

$$
R_{\text {retr }}=R_{A}+R_{B}=\frac{2 \rho}{3 \pi r_{0}} \approx \frac{\rho}{4,71 r_{0}}
$$

We calculate the "internal" resistance (hemisphere A) by integrating the conductivities of the elementary ringshaped areas shown in Fig. 2 to clarify the constriction resistance.

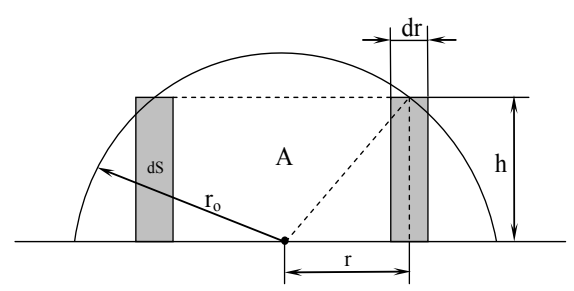

Fig. 2. Clarifying constriction resistance.

The conductivity of the annular region $\mathrm{dr}$ is

$$
G_{h}=\frac{d s}{\sqrt[\rho]{r_{0}^{2}-r^{2}}}
$$

where - the area of the horizontal cross section.

The conductivity of the sphere A is defined as follows:

$$
G_{a}=\int_{0}^{r 0} \frac{2 \pi r}{\sqrt[\rho]{r_{0}^{2}-r^{2}}} d r
$$

After integration within the given limits and after tran- 
sition to the inverse value we obtain an equation for the resistance of the zone $\mathrm{A}$

$$
R_{A}=\frac{\rho}{2 \pi r_{0}}
$$

Then the constriction resistance is defined as the sum

$$
R_{r e t r}=R_{A}+R_{B}=\frac{\rho}{\pi r_{0}}
$$

We obtain an underestimated value in the first version of the calculation and an overestimated value in the second version of the calculation in comparison with the classical formulas.

The most correct result is obtained by integrating of the conductivity in all volume of the half-space. We select for this purpose in the zone B the elementary areas which are the difference of the volumes of two truncated cones with corners at the vertices: $2 \alpha$ и $2(\alpha+d \alpha)$ (see Fig. 3).

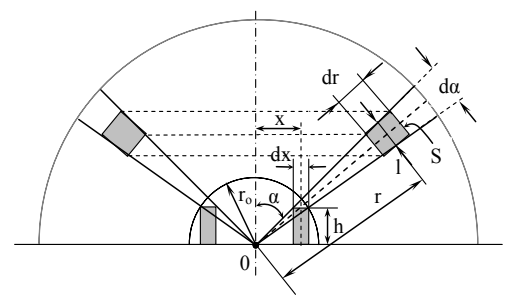

Fig. 3. Clarifying constriction resistance

The conductivity of the ring-shaped volume $\mathrm{dx}$ is

$$
d G_{X}=\frac{2 \pi x d x}{\sqrt[\rho]{x_{0}^{2}-x^{2}}}
$$

For the zone $\mathrm{B}$ area $\mathrm{S}$ and a width of the annular volume dr are:

$$
\mathrm{S}=2 \pi \mathrm{r}^{2} \sin \alpha \mathrm{d} \alpha ; \lambda=\mathrm{rd} \alpha
$$

Then the resistance of the volume of the angle $d \alpha$ of rotation in the zone B:

$$
d R_{B}=\frac{\rho}{2 \pi \sin \alpha d \alpha} \int_{r 0}^{r_{\infty}} \frac{d r}{r^{2}}=\frac{\rho}{2 \pi \sin \alpha d \alpha}\left(\frac{1}{r_{0}}-\frac{1}{r_{m}}\right)
$$

We express the increment $\mathrm{dx}$ and coordinate $\mathrm{x}$ through the angle $\alpha$ :

$$
\begin{aligned}
& d x=r_{0}\left(\sin \alpha+\frac{d \alpha}{2} \cos \alpha\right) d \alpha=r_{0} \sin \alpha d \alpha ; \\
& \mathrm{r}=\mathrm{r}_{0} \sin \alpha ; \\
& d R_{A}=\frac{\rho \cos \alpha}{2 \pi r_{0} \sin ^{2} \alpha d \alpha}
\end{aligned}
$$

The constriction resistance of the element will be found as the sum of the resistances of the elements of zones $\mathrm{A}$ and $\mathrm{B}$ :

$$
d R_{r t r}(\alpha)=\frac{\rho \cos \alpha}{2 \pi r_{0} \sin ^{2} \alpha d \alpha}+\frac{\rho}{2 \pi \sin \alpha d \alpha}\left(\frac{1}{r_{0}}-\frac{1}{r_{m}}\right)
$$

After transformations and simplifications we obtain

$$
d R_{r t r}(\alpha)=\frac{\rho}{2 \pi \sin \alpha d \alpha}\left[\frac{1}{r_{0}}(1+\operatorname{ctg} \alpha)-\frac{1}{r_{r w}}\right]
$$

Taking into account that $r_{m}>r_{o}$ the expression is simplified to

$$
d R_{r e t r}(\alpha)=\frac{\rho(1+\operatorname{ctg} \alpha)}{2 \pi r_{0} \sin \alpha d \alpha}
$$

The integration of the elementary volume conductivity $\mathrm{dG}_{\text {retr }}$ is carried out within the limits giving the full coverage of the considered half-space:

$$
\begin{gathered}
G_{r t r}=\int_{0}^{\pi / 2} \frac{2 \pi r_{0} \sin \alpha}{\rho(1+\operatorname{ctg} \alpha)} d \alpha \\
G_{r t r}=\frac{\pi r_{0}}{\rho \sqrt{2}} \lambda \nu\left(\frac{\sqrt{2+1}}{\sqrt{2-1}}\right) \\
G_{r e t r}=\frac{r_{0}}{\rho} 3,916
\end{gathered}
$$

Then the total constriction resistance approximately is

$$
R_{\text {retr }} \approx \frac{\rho}{3,916 r_{0}}
$$

The exnot frumuln is ${ }^{n n} f_{n d r}=\frac{\rho}{r_{0}} \cdot \frac{\sqrt{2}}{\pi} \ln ^{-1}\left(\frac{\sqrt{2}+1}{\sqrt{2}-1}\right)$

As we see, the expression (23) almost coincides with the Holm formula for the constriction resistance of the round contact pad.

Until now it was about the resistance of the continuous contact area. However, in reality, almost always contact spot is a fractal cluster of fractional dimension with imperfect boundaries [13], [15-16], [24]. In this case, the packing density of cluster elements fractal dimension D should be taken into account when determining the constriction resistance. The dimension D is not dependent on the shape of the cluster, or whether the package of its constituent monomers dense, random or slitted. The fractal dimension of a flat cluster is always less than 2, i.e. less than the size of the topological dimension of space. The packing density depends on the shape of the monomers. Thus, for close packed spheres is about , and at a random packing is reduced to 0,637 . To cover a flat cluster with squares, and three-dimensional with cubes, we can assume that with an unlimited decrease of monomers, the packing density tends to the one. If the size of the element is $r$ and the characteristic cluster size is $r_{k l}$ then we write:

$$
N=\rho_{b l}\left(\frac{r_{b l}}{r}\right)^{D}
$$

in the limit when $\rho_{\mathrm{kl}} \rightarrow 1$,

$$
N=\left(\frac{r_{b l}}{r}\right)^{D}
$$
where

from 


$$
D=\frac{\lg N}{\lg r_{u}-\lg r}
$$

As the parameter of the cluster size, the radius of gyration is used. It is introduced by the ratio $\left.\mathrm{R}_{\mathrm{g}}=\left(<\mathrm{R}^{2}\right\rangle\right)^{1 / 2}$ , where $\mathrm{R}$ is the distance from the considered point of the cluster to its center of mass, angle brackets mean averaging over the distribution of particles in the cluster.

Expression (23) defines only half of the constriction resistance, since defined for half space. Therefore, the total resistance in the case of identical density $\rho$ of the half-spaces is determined by the following expression

$$
R_{\text {retr }}=\frac{\rho}{1,96 \cdot r_{0}} \approx \frac{\rho}{2 r_{0}}
$$

For the spatial defining of clusters instead of the topological dimension, fractional fractal dimension is used. Therefore, the magnitude of the constriction resistance of the cluster depends on its fractal dimension. In view of the above, we write down the constriction resistance formula for fractional objects in the following form:

$$
\mathrm{R}_{\text {retr } \quad \mathrm{kl}}=\mathrm{R}_{\text {retr }} \cdot\left(\mathrm{r}_{\mathrm{kl}} \cdot \mathrm{D}_{\mathrm{f}} \quad\right)
$$

where $R_{\text {retr kl }}$ is the constriction resistance of the fractal cluster, $R_{\text {retr }}\left(r_{k k}\right)$ is the constriction resistance of a circle with a radius equal to the characteristic size of the cluster $\mathrm{r}_{\mathrm{kl}}$, for three-dimensional space

$$
R_{r t r}\left(r_{k l}\right)=\frac{\rho}{2 r_{k l}}, R_{r t r k}=\frac{\rho}{2 r_{u} D_{f}}
$$

$\mathrm{D}_{\mathrm{f}}$ is the cluster's fractal dimension.

The proof of assertion (28) in general form is of considerable complexity. Therefore, a series of experimental studies was carried out to verify the above formula. The results of the experiments, as well as the derivation of the necessary mathematical expressions are given below.

Expression (28) becomes more versatile than the Holm, Ipa, Venart, and Greenwood formulas and makes it quite simple to calculate the constriction resistance of fractal clusters and multifractals. In this aggregation of limited clusters is carried out according to the criterion of their minimum distance from each other (no more than by the size of the characteristic size of the smaller cluster).

To determine the degree of adequacy of formula (28) a series of experiments was carried out on a flat model of current lines. The experimental plant is shown schematically in Fig. 4.

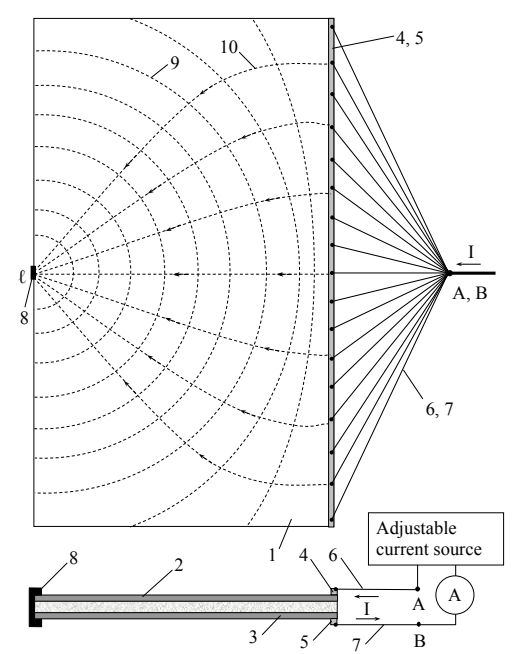

Fig. 4. Experimental setup for measuring the constriction resistance on the conductive plane.

A rectangular sheet of foiled textolite 1 has two copper layers 2 and 3 deposited on both planes. On one side of the sheet, along the edge of the electrically conductive layers, copper buses 4, 5 are soldered, to which two groups of conductors 6, 7 are attached. These groups of conductors are connected by other ends at points A and B, which are connected to an adjustable current source through ammeter $A$. On the other side of sheet 1 , copper jumpers 8 of width $\ell$ are installed, which may be several at different distances from each other. One jumper shown in the figure is a linear analogue of a flat circular contact spot. The constriction resistance of a single jumper is calculated according to the formulas, which are defined below.

Fig. 5 shows a quarter of the conducting plane, which is divided into two halves of a non-conductive straight line $x$ containing a conducting segment of length $2 r_{0}$.

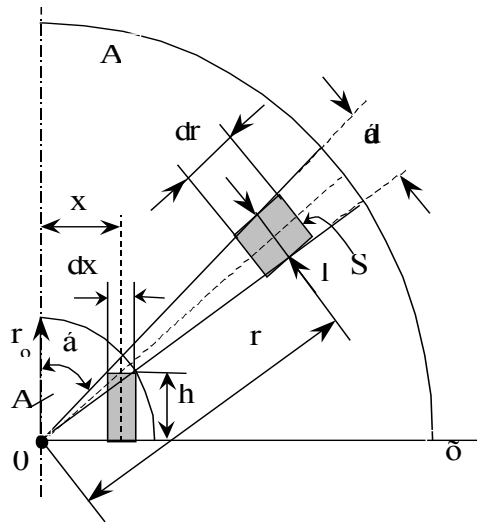

Fig. 5. To determination the constriction resistance on the plane.

The resistance of the flat portion $\mathrm{dx}$ of the inner constriction zone A:

$$
d R_{A}=\rho \cdot \frac{h}{d x}
$$

The increment $\mathrm{dx}$ and the $\mathrm{x}$ coordinate itself is expressed through the angle $\alpha$ :

$$
\begin{aligned}
\mathrm{dx} & =\mathrm{r}_{0} \cdot \sin \alpha \mathrm{d} \alpha ; \\
\mathrm{h} & =\mathrm{r}_{0} \cdot \sin \alpha ; \\
d R_{A} & =\frac{\rho}{d \alpha} .
\end{aligned}
$$


For the "outer" zone B of the half-plane, the width 1 of the annular volume $\mathrm{dr}$ is determined by formula $\mathrm{l}=\mathrm{r} \mathrm{d} \alpha$ , and the resistance of the elementary part $\mathrm{dr}$ is

$$
d R_{r}=\rho \frac{d r}{r d \alpha} .
$$

Then the resistance of the ring sector with the angle $\mathrm{d} \alpha$ is

$$
d R_{B}=\frac{\rho}{d \alpha} \int_{r 0}^{R_{v}} \frac{d r}{r}=\frac{\rho}{d \alpha} \cdot \ln \frac{R_{t_{n}}}{r_{0}} .
$$

We find the resistance of the element as a sum

$$
d R_{r t r}(\alpha)=\frac{\rho}{d \alpha}+\frac{\rho}{d \alpha} \ln \frac{R_{m}}{r_{0}}=\frac{\rho}{d \alpha} \cdot\left(1+\ln \frac{R_{t w}}{r_{0}}\right) .
$$

The conductivity of the constriction element is

$$
d G_{r t r}(\alpha)=\frac{d \alpha}{\rho\left(1+\ln \frac{R_{r m}}{r_{0}}\right)} .
$$

The integration of the conductivity of the elementary volume $\mathrm{dG}_{\text {retr }}$ will be done within the limits giving the full coverage of the considered plane:

$$
\begin{gathered}
G_{r t r}=\frac{d \alpha}{\rho\left(1+\ln \frac{R_{m}}{r_{0}}\right)} \int_{0}^{2 \pi} d \alpha . \\
G_{r t r}=\frac{2 \pi}{\rho\left(1+\ln \frac{R_{r m}}{r_{0}}\right)}
\end{gathered}
$$

Then the total constriction resistance is equal to

$$
R_{\text {retr }}=\frac{\rho}{2 \pi}\left(1+\ln \frac{R_{t n}}{r_{0}}\right)
$$

For the cluster, taking into account the fractal dimension, we get

$$
R_{\text {rtr }}=\frac{\rho}{2 \pi}\left(1+\ln \frac{R_{t w}}{r_{u} D_{f}}\right)
$$

The characteristic cluster size $r_{k l}$ is defined as twice the radius of gyration, which is calculated as follows: 1) we find the radius of the mass center of the linear cluster

$$
R_{c}=\frac{1}{n} \cdot \sum_{1}^{n} r_{i}
$$

where $r_{i}$ is the distance from the origin to the $i$-th element of the cluster; $n$ is the number of cluster members; 2) calculate the radius of cluster gyration:

$$
R_{g}=\sqrt{\frac{1}{n} \sum_{1}^{n}\left(r_{i}-R_{c}\right)^{2}}
$$

and find the numerical value of the fractal dimension:

$$
D_{f}=\frac{\log (n)}{\log \left(\frac{R_{g}}{r_{0}}\right)}
$$

From the current source through the flat copper layers 2, 3 and jumper 8 the current $\mathrm{I}$ is conducted. Measurements of the potential difference on surfaces 2, 3 by a millivoltmeter allow us to construct equipotentials 9 and current lines 10 .
III.

\section{RESULTS AND DISCUSSION}

We will determine the constriction resistance in two ways. The first method is to use for calculation the measured voltage drops on the plane and the magnitude of the current I. The second method is based on applying formula (28) together with expressions (40-43).

In the second case, in the calculations we use only the geometric dimensions of the model and the magnitude of the resistivity of the electrically conductive layer. The accuracy of the coincidence of the calculation results of the constriction resistance, carried out in two ways for different clusters, determined by the location of the jumpers 8 , allows us to view the adequacy of the proposed formula for calculating the constriction resistance.

The specific resistivity of the conductive layer was determined experimentally. For this purpose strap width $\mathrm{S}$ from foil-coated textolite was manufactured. Along it, a current was passed through the conducting layer (up to $70 \mathrm{~A})$ and the voltage drop $\Delta \mathrm{U}$ was measured on a section of a layer of length L. Resistivity was calculated by the formula

$$
\rho=\frac{\Delta U S}{1 L}
$$

Multiple measurements with averaging gave the result $\rho \approx 57 \cdot 10^{-3}$ OM.

Using the same copper jumpers width $\ell=0.0012$ $\mathrm{m}$ linear conductive clusters of various configurations were created, for which the formulas (40-43) were calculated constriction resistance. The voltage drop was measured along a straight line perpendicular to the line of separation of the conducting plane and passing through the mass center of the cluster.

Using the same copper jumpers width $\ell=0.0012$ $\mathrm{m}$ linear conductive clusters of various configurations were created, for which the formulas (40-43) were calculated constriction resistance. The voltage drop was measured along a straight line perpendicular to the line of separation of the conducting plane and passing through the mass center of the cluster.

Fig. 6-11 shows a the calculated and experimental dependences of the constriction resistance $R_{c r}$ on the distance $\mathrm{R}_{\mathrm{m}}$ to the center of mass of the cluster at which the voltage drop was measured.

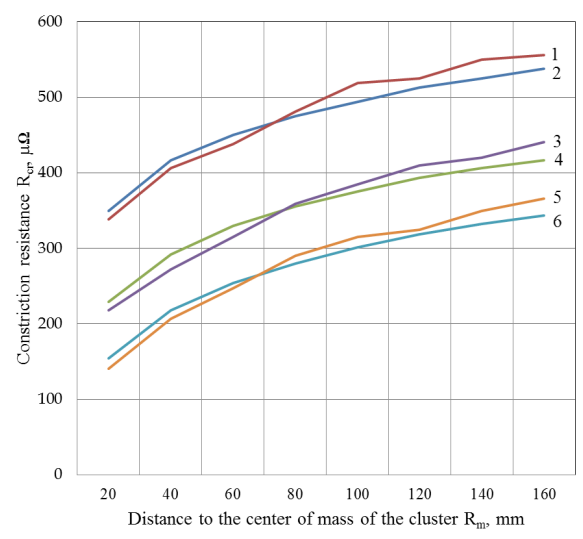

Fig. 6. Dependences $R_{c r}=f\left(R_{m}\right)$ (1-3 elements)

1 - 1 element, experiment, 2 - 1 element, calculate, 3 - 2 elements, experiment, 4 - 2 elements, calculate, 5 - 3 elements, experiment, 6 - 3 elements, calculate 


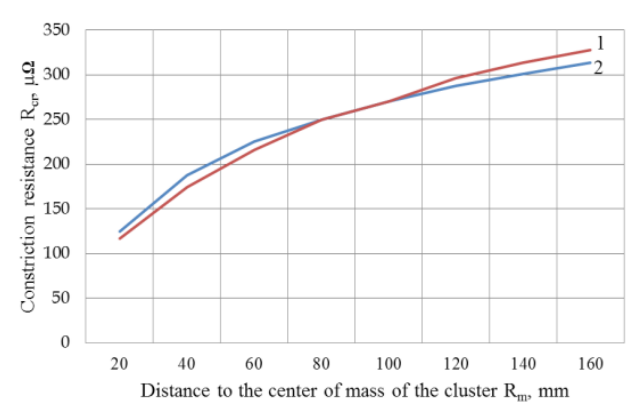

Fig. 7. Dependences $R_{\mathrm{cr}}=f\left(R_{\mathrm{m}}\right)(4$ elements) 1 - 4 elements, experiment, 2 - 4 element, calculate

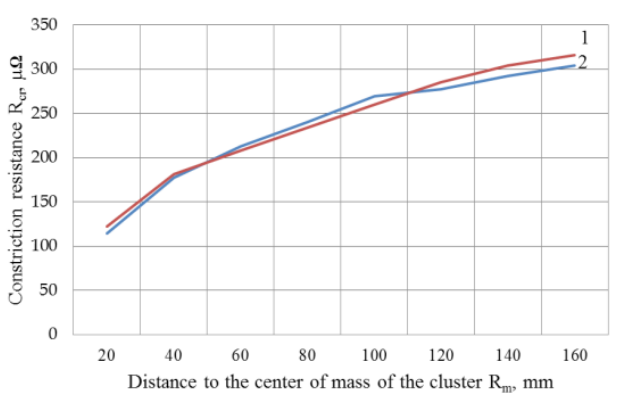

Fig. 8. Dependences $R_{c r}=f\left(R_{m}\right)(5$ elements $)$

1 - 5 elements, experiment, 2 - 5 element, calculate

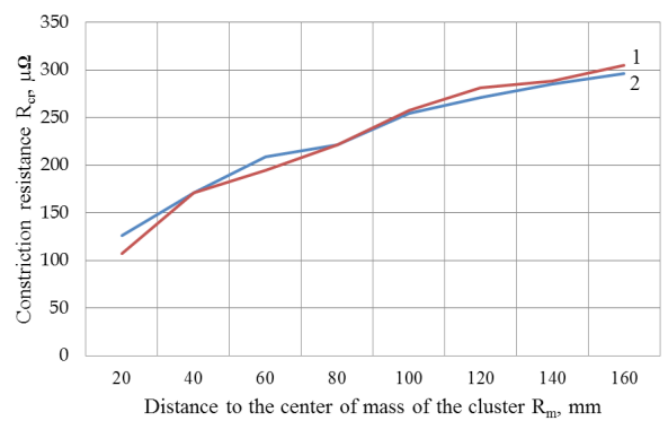

Fig. 9. Dependences $R_{c r}=f\left(R_{m}\right)(6$ elements) 1 - 6 elements, experiment, 2 - 6 elements, calculate

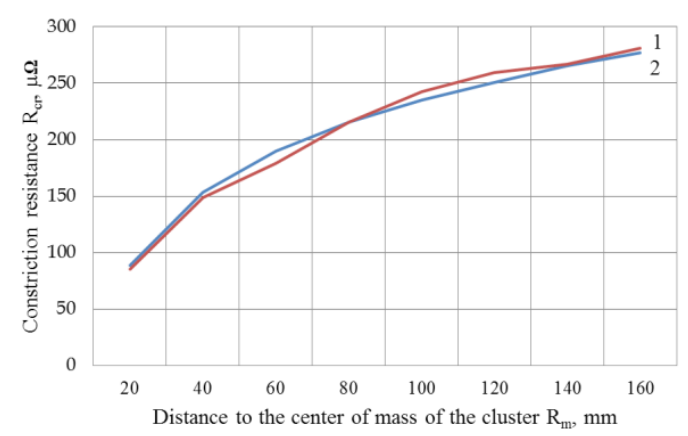

Fig. 10. Dependences $R_{\mathrm{cr}}=f\left(R_{\mathrm{m}}\right)$ (7 elements) 1- 7 elements, experiment, 2 - 7 elements, calculate

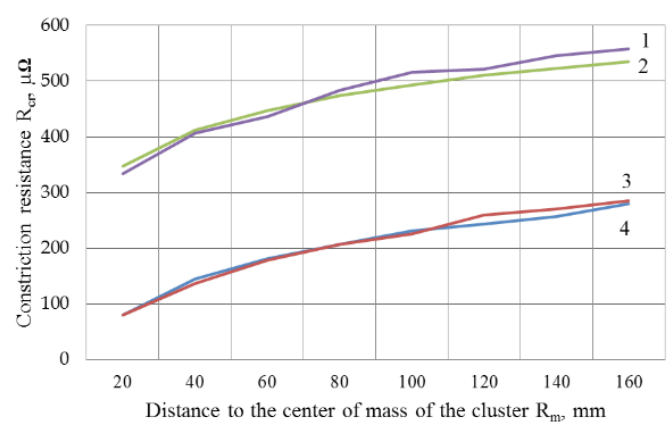

Fig. 11. Dependences $R_{c r}=f\left(R_{m}\right)$ (8-9 elements) 1 - 9 elements, experiment, 2 - 9 elements, calculate 3 - 8 elements, experiment, 4 - 8 elements, calculate

First the voltage drops $\Delta \mathrm{U}_{\mathrm{o}}$ between the bus 5 and the centers of the jumpers 8 was measured. (These voltages are almost equal, since the cluster dimensions are significantly less than the distance to the bus). Then the voltage drops $\Delta \mathrm{U}_{\mathrm{i}}$ between the bus 5 and selected points on the conductive plane 2 was measured. The following formula was used to calculate the experimental constriction resistance value.

$$
R_{\text {rtrexp }}=\frac{\Delta U_{0}-\Delta U_{i}}{I}
$$

The theoretical value of the constriction resistance was found by the formula (40).

\section{CONCLUSION}

A comparison of experimental and theoretical data (Fig. 6-15) indicates a satisfactory rate of adequacy of the formula for the constriction resistance of a cluster, which uses the magnitude of the fractal dimension as a scaling factor. The difference between experimental and theoretical results does not exceed 5\%.

\section{ACKNOWLEDGMENTS}

Due to the fact that the verification of this formula was made using a flat experimental model, the conclusion about adequacy was made taking into account the principle of physical similarity. In addition, on the model using this formula, satisfactory qualitative and quantitative correspondences of the experimental and calculated current-voltage attractors were obtained [14].

\section{REFERENCES}

[1] Holm R. Electric contacts handbook. Landkof N.S. Foundations of Modern Potential Theory, Berlin, Springer, 1973, 424 p.

[2] Merl W. Elektricheskiy kontakt [Electric Contact]. - M.-L., Gosenergoizdat Publ, 1962. (in Russian).

[3] Haken, H. Synergetik. Berlin, Heidelberg, New York, Springer Verlag, 1981. 382 p.

[4] Mandelbrot B.B. The fractal geometry nature. N.Y., Freeman, 1983. $480 \mathrm{p}$.

[5] Feder J. Fractals. New York, Plenum Press, 1988, 283 p.

[6] Smirnov B.M. Fizika fraktal'nykh klasterov. [Physics of fractal clusters]. Moscow, Nauka Publ., 1991. 136 p. (in Russian).

[7] Omel'chenko V.T. Teoriya protsesov na kontaktakh. [Theory of processes at the contacts]. Kharkov. KhGU, Vishcha shkola Publ. 1979. 126 p. (in Russian).

[8] Reutt E.K., Saksonov I.N. Elektricheskie kontakty. [Electric contacts]. M. Voenizdat. 1971. 126 p. (in Russian). 
Environment. Technology. Resources. Rezekne, Latvia Proceedings of the 12th International Scientific and Practical Conference. Volume III, 201-207

[9] Konchits V.V., Meshkov V.V., Myshkin V.V. Tribotekhnika elektricheskikh kontaktov. [Tribotechnique of electrical contacts]. Minsk: Nauka i tekhnika Publ. 1986. 255 p. (in Russian)

[10] Kim E.I., Omel'chenko V.T., Harin S.N. Matematicheskie modeli teplovykh prozessov $v$ elektricheskikh kontaktakh. [Mathematical models of thermal processes in electrical contacts]. Alma-Ata: Nauka Publ. 1977. 236 p. (in Russian).

[11] Ivanova V. S., Balankin A. S., Bunin I. Zh., Oksogoev A. A. Sinergetika i fraktaly v materialovedenii. [Synergetics and fractals in materials science]. Moscow, Nauka Publ., 1994. 384 p. (in Russian).

[12] Fraktaly v fizike [Fractals in Physics] Trudy VI mezhdunarodnogo simpoziuma po fraktalam v fizike. Moscow, Mir Publ., 1988. 672 p. (in Russian).

[13] Vaimann T., Rassõlkin A., Gevorkov L., Kallaste A., Kozyreva O., Plokhov I., Kotkov N., Savraev I., Ilyin A. Reducing Sparking in the Transient Layer of the Sliding Electrical Contact Unit. In: L. Radil, J. Macháček, J. Morávek (Ed.). 19th International Scientifc Conference on Electric Power Engineering (EPE) (223-227). Brno: IEEE. 2018

[14]Plokhov I.V. Kompleksnaya diagnostika $i$ prognozirovanie tekhnicheskogo sostoyaniya uzlov skolzyashchego tokos "ema turbogeneratorov. Doct.Diss. [Complex diagnostics and forecasting of the technical condition of the sliding electrical contact unit of turbo-generators. Doct. Diss.] Sankt-Petersburg. 2001. 362 p. (in Russian).

[15] Plokhov I.V. Model 'dinamiki tokoperedachi cherez skolzyashchiy kontakt. [Dynamic model of current transfer through a slipping contact]. Elektrotekhnika [Electrical Engineering], 2005, no. 2, pp. 28-33. (in Russian)

[16] Plokhov I.V. Issledovanie soprotivleniya styagivaniya elektricheskogo kontakta. [Investigation electric contact contraction resistance]. Elektrotekhnika [Electrical Engineering], 2004 , no. 5, pp. 13-18. (in Russian)
[17] Plokhov I.V. Klasternaya model elektrofriktsionnogo vzaimodeystviya (EFV). [Cluster model of electro-friction interaction]. Trudy Pskovskogo politekhnicheskogo instituta. S.-Peterburg/Pskov, SPbGTU Pub., 1997, no. 1. pp. 55-57. (in Russian)

[18] Greenwod J.A. Constriction resistance and the real area of contact. - British Journal off appl. Physics. 1966. V.17. p.1621-1631.

[19] Plokhov I.V., Savraev I.E. И.E. Vychislitelnaya model razvitiya perkolyacionnykh klasterov kontaktnoy provodimosti. [Computational model of development of percolation contact conductivity clusters.]. Trudy Pskovskogo politekhnicheskogo instituta. S.-Peterburg/Pskov. SPbGTU, 1997, no.1, pp.51-54. (in Russian)

[20] Shklovskiy B.I., Efros A.L. Teoriya protekaniya i provodimost sil'no neodnorodnykh sred [Flow theory and conductivity of highly inhomogeneous mediums]. Uspekhi fizicheskikh nauk. [Advances in the physical sciences]. vol.117, no. 3. 1975. pp.401-435. (in Russian)

[21] Yip F.C., Venart J.E.S. Surface topography effects in the estimation of thermal and electrical contact resistance. - In: Proc. Inst. Mech. Eng., 1968. vol. 182. Pt. 3K. p. 81.

[23] Anca Sorana Popa, Veronica Argeşanu. Tribologic aspects concerning the contact surface roughness, in ase of sliding electric contacts. The annals of University "Dunărea de jos " of gala ti fascicle VIII, 2004. ISSN 1221-4590 TRIBOLOGY pp. 127-131.

[24] Ilyin A., Plokhov I., Savraev I., Kozyreva O., Kotkov N. Forming and overlapping microreliefs in sliding contact simulation model Vide. Tehnologija. Resursi - Environment, Technology, Resources. 2017. 